\title{
Diversity and distribution of macrofungi in the man-made Pitchandikulam Forest of Tamil Nadu, southern India
}

\author{
S. Mani ${ }^{1,3} \&$ V. Kumaresan ${ }^{2}$ \\ ${ }^{1}$ Pitchandikulam Bioresource Centre, Auroville, Tamil Nadu 605101, India \\ ${ }^{2}$ Department of Plant Science, Tagore Arts College, Puducherry 605008, India \\ ${ }^{3}$ Xishuangbanna Tropical Botanical Garden, Chinese Academy of Sciences, Yunnan 666303, P.R. China \\ Email: manitrees@yahoo.com ${ }^{1}$; vkumaresan36@yahoo.com ${ }^{2}$
}

Date of online publication 26 June 2009 ISSN 0974-7907 (online) | 0974-7893 (print)

Editor: V.B. Hosagoudar

\section{Manuscript details: \\ Ms \# 02129 \\ Received 29 January 2009 \\ Final received 04 April 2009 \\ Finally accepted 17 June 2009}

Citation: S. Mani \& V. Kumaresan (2009). Diversity and distribution of macrofungi in the man-made Pitchandikulam Forest of Tami Nadu, southern India. Journal of Threatened Taxa 1(6): 340-343.

Copyright: $\odot$ S. Mani \& V. Kumaresan 2009 Creative Commons Attribution 3.0 Unported License. JoTT allows unrestricted use of this article in any medium for non-profit purposes, reproduction and distribution by providing adequate credit to the authors and the source of publication.

Author Details: S. MANI is currently post doctoral fellow in XTBG, China, and his research is concerned with soil nutrition dynamics in the primary and secondary tropical forests. V. KUMERASAN is currently teaching students, and also undertaking macrofungal diversity research in and around Puducherry.

Author Contribution: SM conducted research in the field, analyzed data and prepared the manuscript. VK helped and provided necessary comments during the study and manuscript preparation.

Acknowledgement: SM is grateful to Mr. Joss Brooks and Mr. M. Eric Ramanujam for their encouragement and constant support throughout the study. We also thank to the anonymous reviewers for their comments.

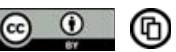

OPEN ACGESS | FREE DOWNLOAD
Abstract: Diversity and distribution of macrofungi in relation to rainfall and humidity in the manmade Pitchandikulam Forest of Tamil Nadu, southern India were studied. The 335 samples from five study plots were composed of 18 species assigned to 14 genera and eight families. Species density ranged from 46 to 87 individuals per plot. Of these, 164 collections were from soil, 147 from leaf litter, 21 from twig and 3 from dead wood. The Shannon diversity index ranged from 0.64 to 0.91 . Overall, four species, i.e. Lycoperdon sp. (63 individuals), Marasmiellus nigripes (58), Termitomyces sp.1 (53) and Marasmiellus sp.1 (39) were recorded from all the plots. The species rank abundance measures were used to visualize distribution. Linear regression indicated no relationship between rainfall and species density. The quantitative analysis of macrofungi revealed a positive trend towards re-creation of forest too.

Keywords: Macrofungi, man-made forest, species abundance, species diversity, species rank.

\section{INTRODUCTION}

Fungi are among the most important organisms in the world, because of their vital role in ecosystem functions, influence on humans and human-related activities (Mueller $\&$ Bills 2004). Although fungi are extremely diverse, they are often ephemeral and cryptic, rendering inventorization difficult (Mueller et al. 2004a). The ranges of some tropical species may not be as restricted as they appear because of the lack of adequate surveys (Lodge et al. 1995). However, knowledge of biodiversity at the community and species level is essential to monitor the effectiveness of, or the need for reservation, and also to follow the effects of natural or artificial disturbance (Packham et al. 2004). The data on fungal diversity and distribution are limited and fragmentary, the consensus is that certain patterns are robust and are worthy of further consideration. The objective of this study was to evaluate the species richness and density of macrofungi by quantitative analysis of species occurring in this man-made forest of the Coastal Tamil Nadu, southern India.

\section{Materials ANd methods}

The present study was conducted in the man-made Pitchandikulam Forest ( $\mathrm{PF}-11^{\circ} 59^{\prime} \mathrm{N}$ \& $\left.79^{\circ} 49^{\prime} \mathrm{E}\right)$, in Auroville green belt area, a well protected 30 ha restored mixed forest. Reforestation programmes began in 1973 by using exotics like, Acacia auriculiformis and Eucalyptus globulus and later there has been a significant shift in priority for restoring the indigenous tropical dry evergreen forest species (Ramanujam \& Anbarasan 2007). The mean annual temperature is $28.63^{\circ} \mathrm{C}$, mean annual rainfall is $213 \mathrm{~mm}$ during the years 2006-2007 (Fig. 1). The climate is tropical asymmetric with the bulk of the rain falling during the northeast monsoon (October to December). The mean relative humidity is $87.11 \%$ during the study period (2006-2007).

The present study was carried out during rainy season between October 2006 and January 2007, the most favorable season for the production of fruit body. Five $20 \mathrm{~m} \mathrm{x}$ $20 \mathrm{~m}$ square plots were established under the different plant communities and the inter distance between the each plots was about $100 \mathrm{~m}$. These plots were established as a part of plant the inventory project in the study sites, and using established plots facilitates comparison of the plant and macrofungal diversity data (Mueller et al. 2004b). There are no standard methods for accurately estimating the macrofungal species richness of an area, based on a sample of the macrofungi (Schmit et al. 1999). Macrofungal fruitbodies were sampled once a week (Oct '06 to Jan '07) from all the five plots. Fruit bodies of a species that occurred scattered and far apart were treated as single individual. In case of small macrofungi occurring in groups/clusters, a frame of $20 \mathrm{~cm} \times 20 \mathrm{~cm}$ was put on top 
Table 1. Total species richness and density of macrofungi in five plots of man-made Pitchandikulam Forest, southern India

\begin{tabular}{lllllll}
\hline Variables & \multicolumn{5}{c}{ Plot } & Total \\
& $\mathbf{1}$ & $\mathbf{2}$ & $\mathbf{3}$ & $\mathbf{4}$ & $\mathbf{5}$ & \\
\hline Species richness & 8 & 9 & 7 & 11 & 10 & 18 \\
Genera & 7 & 7 & 6 & 8 & 7 & 14 \\
Family & 7 & 5 & 7 & 5 & 6 & 8 \\
Density & 79 & 46 & 87 & 70 & 53 & 335 \\
Substratum & & & & & & \\
$\quad$ Dead wood & - & 1 & 2 & - & - & 3 \\
$\quad$ Leaf litter & 40 & 31 & 16 & 20 & 40 & 147 \\
$\quad$ Twig & - & 4 & 7 & 9 & 1 & 21 \\
$\quad$ Soil & 39 & 10 & 62 & 41 & 12 & 164 \\
Shannon index & 0.75 & 0.87 & 0.64 & 0.91 & 0.88 & \\
\hline
\end{tabular}

of the fruit body clusters and those fruit bodies inside the frame was treated as single individual of a species. When the fungi were not identified to the species level, numbers were given to differentiate species belonging to the same genera after studying the morphological and anatomical dissimilarity. Shannon diversity index $\left(H^{\prime}=\Sigma-\left\{p_{i}^{*} \ln \left(p_{i}\right)\right\}\right.$, where $p i$ is the proportion of the $i$ th species) was calculated to understand species share in the study plots (Magurran 2004).

\section{Results ANd Discussion}

This study is restricted to 335 collections made from the five study plots and recording 18 species belonging to 14 genera distributed among 8 families. Species density ranged from 46 to 87 individuals per plot (Table 1 ). There were four types of substrata that influenced the macrofungi, three of them were plant material above the soil and another supported by soil. Of the total collection, $164(49 \%)$ were from soil, 147 (43.9\%) from leaf litter, $21(6.2 \%)$ from twig and 3 (0.9\%) from dead wood (Table 1). Lodge et al. (1995) summarized that species richness was apparently less strongly related to host diversity in large, inclusive groups that contain many decomposers. The Shannon diversity index scored low (0.64) in plot 3 to high (0.91) in plot 4. The other three plots 1,2 , and 5 scored intermediate 0.75 , 0.87 and 0.88 , respectively. Four species: Lycoperdon sp. (18.8\%;
63 individuals in total), Marasmiellus nigripes (17.3\%; 58), Termitomyces sp.1 (15.8\%; 53) and Marasmiellus sp.1 (11.64\%; 39 ) were recorded in all the five plots with high density (Table 2). Nine species scored less than 10 individuals with two species, Calocera sp. and Thelephora ramarioides recorded one each in plot 2 (Table 2 ). The distribution of some species may not be restricted as they appear but for inadequate survey. To understand the biodiversity of this group, long term survey is required (Arnolds 1992; Vogt et al. 1992).

To visualize species abundance distribution, the species rank abundance of five plots was used (Fig. 2). Each species was sorted in descending order, and the proportion of the total number of individuals for each species was plotted on the log scale against the species rank. Plots 1 and 3 showed a steep gradient indicating low evenness as the high ranking species have much higher abundance than the low ranking species (Fig. 2). A shallow gradient indicates high evenness as the abundance of different species are similar in plots 2, 4 and 5 (Fig. 2; Table 2). Species present in more than one plot tended to fruit maximally during the same year in different plots than expected by chance alone. Moderate to highly productive species were sometimes absent in productive years. These two observations together are considered an indication for the specificity of species apart from the general productivity of those years. It appears, unknown factors determine the species composition of the assemblage and that a productivity factor determines the number of fruit bodies that eventually would appear (Straatsma \& Krisai-Greilhuber 2003).

A simple linearregression showed no relation to rainfall and species density, may be due to less rainfall (Figure 3a). But, the relationship between humidity and density was neutral in the study plots that could be due to moisture retains (Figure $3 \mathrm{~b})$. These two observations and assumptions show an error because of the short period of collection, poor number of rainy days and single survey of the site (not monitored) as uncorrelated with the independent variables. None the less, this method may be used to predict a positive relationship between humidity and species abundance because more number of fruit bodies were collected from leaf litter and soil substratum (Table 1). Lindblad (2001) observed that the fruit

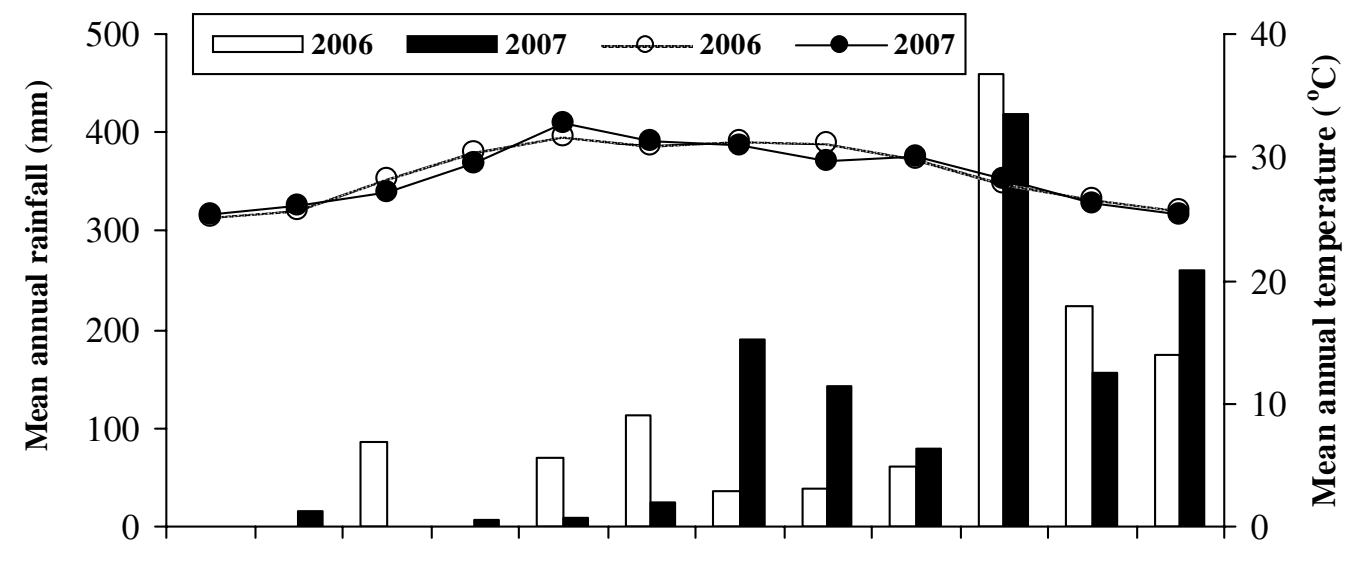

Jan Feb Mar Apr May Jun Jul Aug Sep Oct Nov Dec

Month

Figure 1. Monthly mean annual rainfall $(\mathrm{mm})$ (dark and open bars) and mean annual temperature $\left({ }^{\circ} \mathrm{C}\right)$ (dark and open circles) for 2006 and 2007 of the study area. 
Table 2. Total individual species density of macrofungi in the five plots

\begin{tabular}{|c|c|c|c|c|c|c|c|c|c|}
\hline \multirow[t]{2}{*}{ Sno. } & \multirow[t]{2}{*}{ Species name } & \multirow[t]{2}{*}{ Family } & \multirow[t]{2}{*}{ Substratum } & \multirow[b]{2}{*}{1} & \multirow[b]{2}{*}{2} & \multicolumn{3}{|c|}{ Plot } & \multirow[t]{2}{*}{ Total } \\
\hline & & & & & & 3 & 4 & 5 & \\
\hline 1. & Lycoperdonsp. & Lycoperdaceae & Soil & 11 & 5 & 27 & 19 & 1 & 63 \\
\hline 2. & Marasmiellus nigripes & Tricholomataceae & Leaf litter & 32 & 6 & 1 & 4 & 15 & 58 \\
\hline 3. & Termitomyces sp. 1 & Amanitaceae & Soil & 2 & 4 & 32 & 8 & 7 & 53 \\
\hline 4. & Maramiellus sp. 1 & Tricholomataceae & Leaf litter & 3 & 7 & 15 & 7 & 7 & 39 \\
\hline 5. & Agaricus sp. & Agaricaceae & Soil & 13 & - & - & 11 & - & 24 \\
\hline 6. & Marasmius sp. 2 & Tricholomataceae & Leaf litter & - & 11 & - & 6 & 6 & 23 \\
\hline 7. & Marasmius sp.1 & Tricholomataceae & Leaf litter & 5 & 7 & - & 3 & 5 & 20 \\
\hline 8. & Mycena sp. & Tricholomataceae & Twig & - & 4 & - & 8 & 1 & 13 \\
\hline 9. & Macrolepiota sp. & Agaricaceae & Soil & 8 & - & - & - & 2 & 10 \\
\hline 10. & Gerronemasp. & Tricholomataceae & Twig & - & - & 7 & 1 & - & 8 \\
\hline 11. & Marasmius sp.3 & Tricholomataceae & Leaf litter & - & - & - & - & 7 & 7 \\
\hline 12. & Coprinus sp. & Coprinaceae & Soil & 5 & - & - & - & - & 5 \\
\hline 13. & Cystoagricus trisulphuratus & Agaricaceae & Soil & - & - & 3 & - & - & 3 \\
\hline 14. & Pisolithus sp. & Sclerodermataceae & Soil & - & - & - & 1 & 2 & 3 \\
\hline 15. & Camarophyllus sp. & Tricholomataceae & Dead wood & - & - & 2 & - & - & 2 \\
\hline 16. & Termitomyces sp.2 & Amanitaceae & Soil & - & - & - & 2 & - & 2 \\
\hline 17. & Calocerasp. & Dacrymycetaceae & Dead wood & - & 1 & - & - & - & 1 \\
\hline \multirow[t]{2}{*}{18.} & Thelephora ramarioides & Thelephoraceae & Soil & - & 1 & - & - & - & 1 \\
\hline & Grand total & & & 79 & 46 & 87 & 70 & 53 & 335 \\
\hline
\end{tabular}

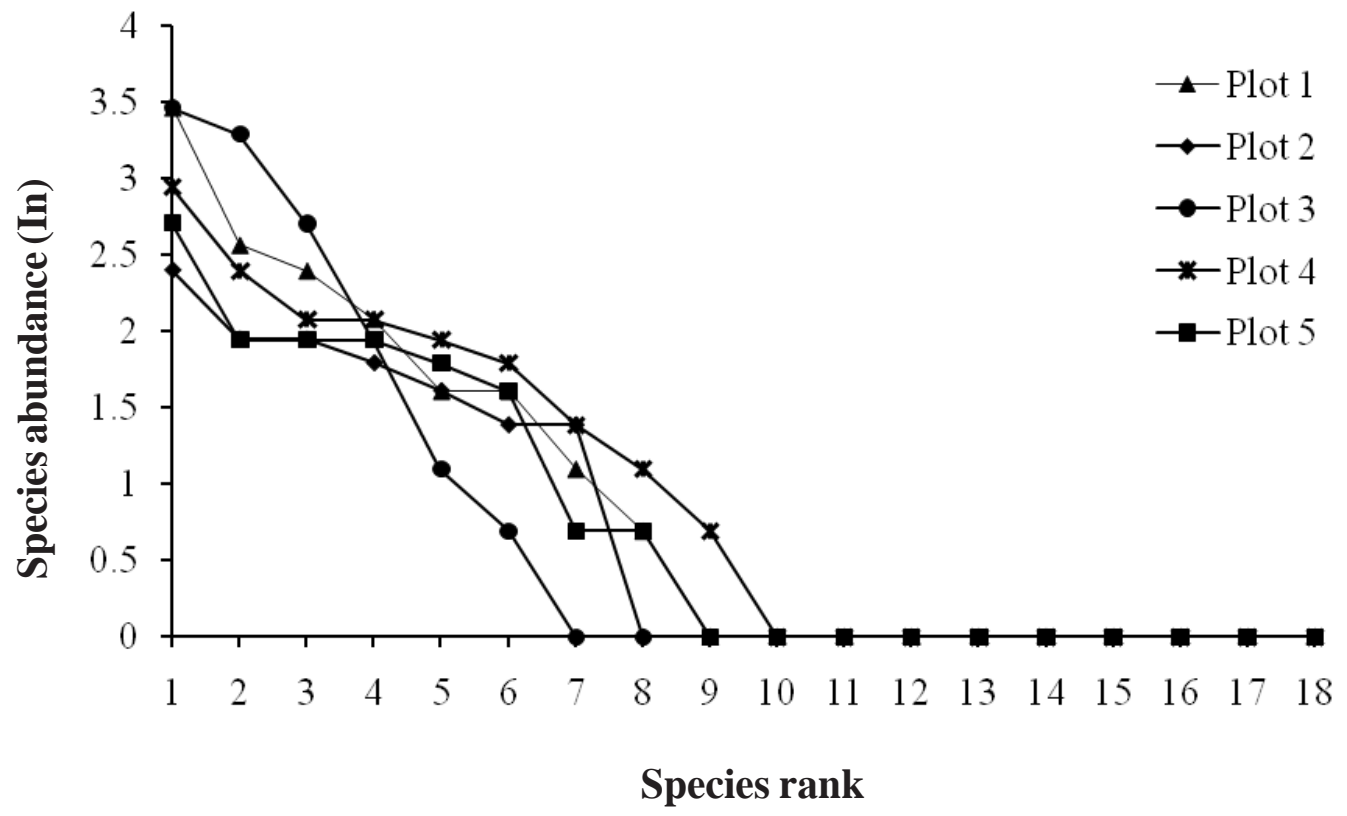

Figure 2. Species rank abundance of the five plots in the man-made Pitchandikulam Forest of Tamil Nadu, southern India.

bodies are possibly produced at the same wood moisture level in all forests, and this level was reached after heavy rain in the dry forest and after a dry period in the moist and wet forests. However, quantitative data of macrofungal diversity have been used to determine whether mushroom species follow the ecological rule that the local abundance of a species is related to the size of its geographic range (Gaston 1994; Johnson 1998). In a natural ecosystem different processes could become prominent at different stages of the seasonal cycle, and the changes in the patterns observed might, therefore, have reflected temporal changes in the overall ecosystem functioning (Krivtsov et al. 2004). In the present study the quantitative analysis of macrofungi revealed their diversity and distribution in the tropical man-made forest, suggesting recreation of tropical forests not only influence fauna and flora, but also macrofungi considerably.

\section{References}

Arnolds, E. (1992). The analysis and classification of fungal communities with special reference to macrofungi, pp. 7-47. In: Winterhoff, W (ed.). Fungi in vegetation science. Kluwer Academic Publishers, Dordrecht, 256pp.

Gaston, K.J. (1994). Rarity. Chapman and Hall, London, 205pp.

Johnson, C.N. (1998). Species extinction and the relationship between distribution and abundance. Nature 394(6690): 272-274.

Krivtsov, V., B.S. Griffiths, R. Salmond, K. Liddell, A. Garside, T. Bezginova, J.A. Thompson, H.J. Staines, R. Watling \& J.W. Palfreyman (2004). Some aspects of interrelations between fungi and other biota in forest soil. Mycological Research 108(8): 933-946.

Lindblad, I. (2001). Diversity of poroid and some corticoid woodinhabiting fungi along the rainfall gradient in tropical forests, Costa Rica. Journal of Tropical Ecology 17(3): 353-369.

Lodge, D.J., I. Chapela, G. Samuels, F.A. Uecker, D. Desjardin, E. Horak, Jr.O.K. Miller, G.L. Hennebert, C.A. Decock, J. Ammirati, Jr.H.H. Burdsall, P.M. Kirk, D.W. Minter, R. Hailing, T. Laessøe, 

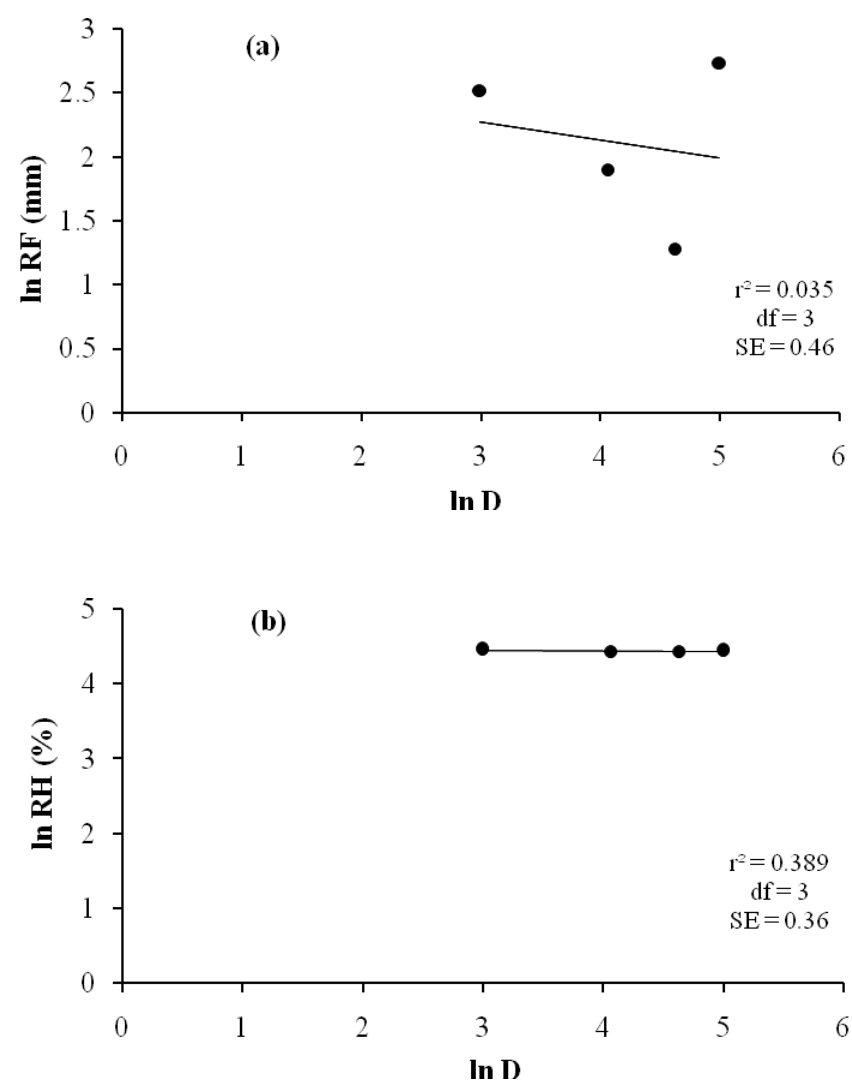

Figure 3. Regression between (a) logarithm of rainfall and logarithm density, and (b) logarithm of relative humidity and logarithm density. Each dot corresponds to total of individuals from the collection periods (4 months).

RF - Relative rainfall; RH - Relative humidity; D - species density; df - degree of freedom; SE - Standard Error
G.M. Mueller, S. Huhndorf, F. Oberwinkler, D.N. Pegler, B. Spooner, R.H. Petersen, J.D. Rogers, L. Ryvarden, R. Watling, E. Turnbull \& A.J.S. Whalley (1995). A Survey of Patterns of Diversity in Non-Lichenized Fungi. Mitt. Eidgenöss. Forsch. Anst. Wald Schnee Landsch 70: 157-173.

Magurran, A. (2004). Measuring biological diversity. Blackwell Science Ltd., UK, 260pp.

Mueller, G.M. \& G.F. Bills (2004). Introduction, pp.1-4. In: Mueller, G. M., G.F. Bills \& M.S. Foster (eds.). Biodiversity of fungi: inventory and monitoring method. Elsevier Academic Press, San Diego, 777pp.

Mueller, G.M., G.F. Bills \& M.S. Foster (2004a). Biodiversity of fungi: Inventory and Monitoring Methods. Elsevier Academic Press, San Diego, $777 \mathrm{pp}$.

Mueller, G.M., J.P. Schmit, S.M. Hubndorf Leif Ryvarden, T.E. O’Dell, D.J. Lodge, P.R. Leacock, M. Mata, L. Umania, Q. Wu \& D.L. Czederpiltz (2004b). Recommended protocols for sampling. macrofungi, pp.170-171. In: Mueller, G.M., G.F. Bills \& M.S. Foster (eds.). Biodiversity of fungi: Inventory and Monitoring Methods. Elsevier Academic Press, San Diego, 777pp.

Packham, J.M., T.W. May, M.J. Brown, T.J. Wardlaw \& A.K. Mills (2002). Macrofungal diversity and community ecology in mature and regrowth wet eucalypt forest in Tasmania: A multivariate study. Austral Ecology 27(2): 149-161.

Ramanujam, M.E \& R. Anbarasan (2007). A preliminary report on the vertebrate diversity of the Kaliveli watershed region. Zoos' Print Journal 22(3): 2608-2616.

Schmit, J.P., J.F. Murphy \& G.M. Mueller (1999). Macrofungal diversity of a temperate oak forest: a test of species richness estimators. Canadian Journal of Botany 77: 1014-1027.

Straatsma, G. \& I. Krisai-Greilhuber (2003). Assemblage structure, species richness, abundance, and distribution of fungal fruit bodies in a seven year plot-based survey near Vienna. Mycological Research 107(5): 632-640.

Vogt, K.A., J. Bloomfield, J.F. Ammirati \& S.R. Ammirati (1992). Sporocarp production by basidiomycetes, with emphasis on forest ecosystems, pp.563-581. In: Carroll, G.C. \& D.T. Wicklow (eds.). The Fungal Community. Marcel Dekker, New York, 975pp. 